КОЗЛОВА Татьяна Захаровна - доктор социологических наук, ведущий научный сотрудник Института социологии ФНИСЦ РАН (117218, Россия, г. Москва, ул. Кржижановского, 24/35, кopn. 5; tatiana_kozlova@mail.ru)

\title{
СОЦИАЛЬНО-ПСИХОЛОГИЧЕСКОЕ САМОЧУВСТВИЕ РОССИЯН ПО ВОЗРАСТНЫМ ГРУППАМ
}

\begin{abstract}
Аннотация. В статье рассматривается социально-психологическое самочувствие россиян по возрастным группам: 19-30; 31-40; 41-50; 51-60; старше 60 лет. Статья основана на материалах социологического исследования, проведенного Институтом социологии РАН в конце 2016 г. Результаты исследования показали, как меняется с возрастом повседневное эмоционально-психологическое состояние человека. В молодом и среднем возрасте преобладает спокойное состояние. После 50 лет (ближе к пенсии) увеличиваются такие составляющие социально-психологического состояния россиян, как тревога, страх.
\end{abstract}

Ключевые слова: россияне, возраст, социально-психологическое самочувствие, эмоциональный подьем, тревога

$\mathrm{C}$ оциально-психологическое самочувствие человека - это его обычное повседневное эмоционально-психологическое состояние, которое определяется не только удовлетворенностью составляющими образа жизни (уровнем жизни, ее качеством, стилем), но и реализацией социальной справедливости распределения приоритетов социального вознаграждения в обществе ${ }^{1}$.

Объект нашего исследования - возрастные группы граждан России (в возрасте от 18 лет и старше). Возраст является важной характеристикой личности. Он - индикатор биологического и психологического статуса человека, а значит, в определенных границах, и его социальной активности. Мы берем градацию по возрастным группам, предложенную психологом Б.Г. Ананьевым: 1) 19-30 лет; 2) 31-40 лет; 3) 41-50 лет; 4) 51-60 лет; 5) старше 60 лет [Ананьев 1997: 341344].

Предмет исследования - социально-психологическое самочувствие людей перечисленных выше возрастных групп. Эмпирическая база - репрезентативное всероссийское социологическое исследование, которое провел Институт социологии РАН в конце 2016 г. $N=4000$ чел.

В течение жизни человек проходит несколько этапов жизни (возрастных интервалов). Надо отметить, что основой классификации отдельных периодов жизненного цикла человека является признание противоречивого единства биологического и социального. Соответственно изменениям биологического состояния человека происходят изменения его социально-психологических характеристик, причем последние оказывают воздействие и на процессы физического старения, сдерживая или ускоряя его. С возрастом происходит снижение умственных способностей и сужение сферы мотивации.

Построить концепцию мотивации, основанную на анализе возрастных возможностей личности, попытались американские психологи [Kuhlen 1968]. Они предложили две модели мотивации, характерные для различных возрастных периодов жизни. Первая модель - для молодого и зрелого возраста (20-50 лет), когда человеку сопутствуют достижение целей и успех. В этот период жизни про-

\footnotetext{
1 Сорокина Е.Г. 2017. Самочувствие социальное. - Российская энциклопедия социальной работы (под общ. ред. Е.И. Холостовой). ИТК «Дашков и К». С. 691-692.
} 
исходит расширение сферы потребностей, а вместе с ней - и сферы мотивации. У молодых людей наблюдается активное стремление добиться цели, ориентация на достижение успеха во всем - в карьере, экономической обеспеченности и пр. Формируется потребность «быть впереди». Вторая модель - для человека в пожилом и преклонном возрасте. В этот период происходит сужение сферы потребностей, а вместе с ней - и сферы мотивации. У старых людей ухудшается здоровье, они становятся менее энергичными и начинают «перемещаться» от более значительных и успешных ролей к менее значительным и успешным. Если в молодые годы для психологического равновесия личности необходима активная деятельность, то в старом возрасте у большинства людей это равновесие сопровождается пассивностью, мотивацией «к отставке», которая является средством избежать страха в предчувствии социального отвержения. У старых людей мера тревоги в значительной степени зависит от самооценки, которая тесно связана с уровнем самореализации.

Наряду с изменением сферы мотивации с возрастом изменяется и вторая группа психических свойств - умственные способности. Западные ученые (Дж. Биррен, Дж. Ботвинник, Д. Векслер и др.,), исходя из проведенных исследований, пришли к выводу, что с возрастом происходят прогрессивные изменения умственных способностей людей (исключая речь и словарный запас). Однако, по их мнению, у отдельно взятых людей некоторые способности могут сохраняться до глубокой старости. Речь идет о гетерохронности в отношении умственных способностей [Botwinick 1967]. Некоторые геронтологи склонны рассматривать жизненный путь как трехфазовую схему: подготовительный период (социализация), активный период (до пенсии), фаза покоя - пенсионный период [Clemens, Backes 1998].

Каково социально-психологическое самочувствие у людей различных возрастных групп, как оно меняется с возрастом? Ответ на этот вопрос автор статьи получила, анализируя репрезентативное всероссийское социологическое исследование, проведенное Институтом социологии РАН в конце 2016 г. $N=4000$ чел. Респондентам был задан вопрос: «Как бы Вы охарактеризовали свое обычное, повседневное эмоционально-психологическое состояние?» Для ответа на этот вопрос респондентам были предложены альтернативы (см. табл. 1).

Таблииа 1

\section{Распределение оценок россиянами социально-психологического самочувствия, \%}

\begin{tabular}{|l|c|c|}
\hline $\begin{array}{c}\text { Альтернативы ответов на вопрос: «Как бы Вы } \\
\text { охарактеризовали свое обычное повседневное } \\
\text { эмоциольно-психогическое состояние? }\end{array}$ & $\begin{array}{c}\text { Среди всех } \\
\text { опрошенных }\end{array}$ & $\begin{array}{c}\text { В возрасте } \\
\mathbf{1 8 - 3 0} \text { лет }\end{array}$ \\
\hline Ощущаю эмоциональный подъем & 4 & 8 \\
\hline Чувствую себя спокойно, уравновешенно & 44 & 55 \\
\hline Нахожусь в состоянии безразличия, апатии & 11 & 9 \\
\hline Ощущаю тревогу & 29 & 77 \\
\hline Чувствую раздражение & 9 & 2 \\
\hline Ощущаю чувство озлобленности & 2 & 1 \\
\hline Ощущаю чувство агрессии & 1 & 7 \\
\hline
\end{tabular}

В таблице 1 приведены данные по всей совокупности опрошенных, а также данные первой возрастной группы 18-30 лет.

Если внимательно посмотреть на предложенные альтернативы для ответа на 
вопрос об эмоционально-психологическом самочувствии граждан, то можно увидеть, что содержание альтернатив идет в порядке убывания - от социальнопсихологического самочувствия с положительным знаком («ощущаю эмоциональный подъем», «чувствую себя спокойно, уравновешенно»), к альтернативам социально-психологического самочувствия с отрицательным знаком («нахожусь в состоянии безразличия, апатии», «ощущаю тревогу», «чувствую раздражение», «ощущаю чувство озлобленности»).

Остановимся на данных повседневного эмоционально-психологического самочувствия всех опрошенных. В первой колонке табл. 1 приведены данные социально-психологического самочувствия россиян в 2016 г. Итак, у половины россиян $(48 \%)$ социально-психологическое самочувствие со знаком плюс, т.е. были выбраны альтернативы «ощущаю эмоциональный подъем» и «чувствую себя спокойно, уравновешенно». Надо заметить, что значения этих положительных характеристик социально-психологического самочувствия россиян несколько понизились по сравнению с предыдущим, 2015 г. [Латова 2016: 46]. Так, в 2015 г. 5\% опрошенных россиян отметили альтернативу «ощущаю эмоциональный подъем» и 45\% - «чувствую себя спокойно, уравновешенно». В то же время такие характеристики самочувствия россиян, как «тревога, страх» несколько повысились в 2016 г. по сравнению с 2015 г. Повысилась в 2016 г. и такая негативная характеристика социально-психологического самочувствия, как «раздраженность, озлобленность, агрессия». Если в 2015 г. она равнялась $10 \%$, то в 2016 г. - 12\%. На что стоит обратить внимание, так это на снижение апатии в 2016 г. В 2015 г. уровень безразличия, подавленности и апатии россиян составлял 12\%, в 2016 г. - 11\% [Латова 2016: 46]. Ведущие специалисты Института социологии РАН дали анализ динамики личного социально-психологического состояния россиян в 2015 г.: «С момента начала кризиса к этому времени [осень 2015 г.] прошел год. Однако результаты предшествующего мониторинга в марте 2015 года продемонстрировали, что, во-первых, влияние кризиса оказалось не настолько сильным, как этого можно было бы ожидать, а во-вторых, он не привел к массовой депрессии или отчуждению, а вызвал умеренное чувство тревоги» [Латова 2016: 45]. Подчеркивается, что «не следует забывать о том, что любое явление (особенно негативное и долго длящееся) зачастую имеет отложенный эффект» [Латова 2016: 45]. Этот отложенный эффект и сказался на несколько пониженных данных положительных сторон социально-психологического самочувствия россиян в 2016 г. по сравнению с 2015 г.

Переходим к анализу социально-психологического самочувствия россиян по возрастным группам.

Первый интервал взрослой жизни - 18-30 лет. У молодого человека поставлены жизненно важные цели, сформировался план их выполнения. Определение генеральной цели (дерева целей) жизни является важным событием первой стадии самореализации личности. Вместе с тем первый этап реализации личности прежде всего связан с процессом адаптации как в профессии, так и в семье (если она уже создана).

Молодежь, вступая в жизнь, сталкивается с рядом проблем. Одна из них проблема трудоустройства. Выпускники учебных заведений (при отсутствии распределения на работу) сами пытаются найти себе подходящее занятие. Не всегда им это удается с первого раза, т.к. у них отсутствует практика. По данным Росстата, в возрастной группе 18-30 лет самый высокий процент безработных (среди них имеют высшее и среднее профессиональное образование 60,9\%)1.

1 Россия в цифрах. 2017: краткий статистический сборник. М.: Росстат. 2017. С. 107. 
Это не значит, что молодые люди не хотят работать. Они находятся в поиске «своей» работы. Исследования экономиста В.А. Гневашевой (2012) показали, что молодежь нуждается в поддержке государства, которое могло бы создать для нее рынок труда. О проблеме трудоустройства молодежи говорил и президент В.В. Путин в послании Федеральному собранию (2018 г.) Так, по его мнению, профориентацией молодежи нужно начинать заниматься со школы. «Билет в будущее» - так он назвал подготовку молодых людей к будущим профессиям.

Говоря о проблемах молодежи, надо отметить исследования Ю. Зубок (2011). Она подчеркивает, что не у всех молодых людей сформировались определенные социальные установки. Такую молодежь несложно переориентировать в любом направлении: от крайне положительного (полезный для общества труд, занятие спортом) до крайне отрицательного (употребление наркотиков, безделье и пр.). На наш взгляд, одна из задач старшего поколения - направлять энергию молодежи в положительное русло, например в волонтерское движение.

Как видно из табл. 1, при многообразии проблем у молодежи социальнопсихологическое самочувствие лучше, чем у респондентов других возрастных групп. Так, если по всему массиву опрошенных только 4\% ощущали эмоциональный подъем, то среди молодых респондентов таковых оказалось 8\%. Кроме того, такая значимая характеристика социально-психологического самочувствия респондентов, как «чувствую себя спокойно и уверенно» для возрастной группы молодых опрошенных оказалась гораздо выше, чем для респондентов всего массива (55\% против 44\%).

Молодежь, несмотря на временные неурядицы в своей жизни, с оптимизмом смотрит в будущее. Некоторые молодые люди настоящую и будущую жизнь воспринимают восторженно, другие - просто со знаком плюс. У них большое стремление добиться поставленной цели, сильная мотивация, умственные способности на пике развития. Все впереди (и только хорошее).

В табл. 2 отражены результаты исследования социально-психологического самочувствия по двум возрастным группам: 31-40 лет и 41-50 лет. Эти две возрастные группы схожи как по своим социально-психологическим, так и социально-экономическим характеристикам.

Таблица 2

\section{Распределение оценок россиянами социально-психологического самочувствия, \%}

\begin{tabular}{|c|c|c|c|}
\hline \multirow{2}{*}{$\begin{array}{c}\text { Альтернативы ответов на вопрос: «Как бы Вы } \\
\text { охарактеризовали свое обычное повседневное } \\
\text { эмоционально-психологическое состояние?» }\end{array}$} & \multirow{2}{*}{$\begin{array}{c}\text { Среди } \\
\text { всех } \\
\text { опрошенных }\end{array}$} & \multicolumn{2}{|c|}{ Возрастные группы, лет } \\
\hline & & $31-40$ & $41-50$ \\
\hline Ощущаю эмоциональный подъем & 4 & 5 & 2 \\
\hline Чувствую себя спокойно, уравновешенно & 44 & 43 & 42 \\
\hline Нахожусь в состоянии безразличия, апатии & 11 & 14 & 12 \\
\hline Ощущаю тревогу & 29 & 27 & 30 \\
\hline Чувствую раздражение & 9 & 8 & 9 \\
\hline Ощущаю чувство озлобленности & 2 & 2 & 3 \\
\hline Ощущаю чувство агрессии & 1 & 1 & 1 \\
\hline
\end{tabular}

Второй интервал взрослой жизни - человек в возрасте от 31 до 40 лет. Освоена профессия. Это период расцвета всех жизненных сил, период наиболее активной реализации поставленных целей. Ученые Санкт-Петербургского универси- 
тета Р.А. Зобов и В.Н. Келасьев так пишут об этом возрастном периоде в жизни человека: «Продолжается профессиональный рост, означающий самореализацию. В случае социальной успешности повышается общая мотивация, происходит творческое развитие средствами профессии. Субъективно этот возраст переживается как апогей жизни, эти годы - период оптимума профессиональных достижений. На этой фазе обнаруживается различие стилей жизни, критериев жизненного успеха. В целом же возраст 30-40 лет характеризуется как время накопления относительно постоянных материальных средств и социальных связей, лидерства в различных видах деятельности» [Зобов, Келасьев 2008: 233]. Анализ эмпирических данных исследования показал, что в этой возрастной группе почти половина опрошенных респондентов отметили, что у них социально-психологическое самочувствие со знаком плюс (5\% «ощущали эмоциональный подъем» и 43\% отметили: «Чувствую себя спокойно, уравновешенно»). Это самая активная, жизнеспособная возрастная группа. Она все время находится на подъеме, решает важные вопросы, совершает значимые поступки. Это возраст профессиональной зрелости, когда еще достаточно хорошее здоровье, достаточно сил. В этот период человек отдает накопленные ранее знания, передает свой опыт молодым коллегам. Среди людей этой возрастной когорты много руководителей в разных сферах производства и науки. Из данных табл. 2 в этой возрастной группе несколько удивляет значение показателя «нахожусь в состоянии безразличия, апатии». Этот показатель у возрастной группы, фактически определяющей многие направления развития страны, равен 14\%. Однако ученые считают, что «безразличие и апатия - чувства негативные, но являющиеся защитными реакциями организма на стрессовые ситуации, т.е. с определенной долей вероятности ориентированные на восстановление психической энергии позитивного общего настроя» [Латова 2016: 47].

Третий период взрослой жизни человека - возраст 41-50 лет. В профессиональной деятельности человек достигает высшей квалификации. Человек знает, что стоит в преддверии пенсии. Поэтому он как никогда стремится передать другим, более молодым сотрудникам свои знания и умение. Для него самореализация в этот период - увидеть, что его ученики переняли его опыт, достигли совершенства в профессии. Анализ эмпирических данных исследования показал, что у этой возрастной группы только $2 \%$ респондентов ощущают «эмоциональный подъем» и 42\% «чувствуют себя спокойно, уравновешенно». Надо отметить, что с этой возрастной группы начинает расти такой показатель социально-психологического самочувствия, как «ощущаю тревогу». Для этой возрастной группы он равен 30\%. Чем старше человек, тем сильнее тревога. С возрастом (после 50 лет) люди начинают задумываться: «А что там впереди?» Какая жизнь их ждет, когда они перестанут определять свое положение (прежде всего, материальное), а будут зависеть от социальной помощи государства, от помощи своих близких?

Надо заметить, что, отмечая пятидесятилетие, некоторые люди уже оглядываются назад, задумываются о прошлом и пытаются ответить на вопрос: «Что я сделал за полвека своей активной жизни?» То есть, они уже предварительно начинают подводить итоги своего жизненного пути. Что полезного сделал для людей, кого оставил продолжать свое дело? Думают они и о том, удалась ли у них жизнь или нет, были ли реализованы планы, сформулированные в молодые годы? Автор этой статьи провела исследование среди пожилых людей пенсионного возраста о их жизненной реализации. Результаты этого исследования приведены ниже.

В таблице 3 отражены результаты исследования социально-психологического самочувствия по двум возрастным группам: 51-60 лет и старше 60 лет. 
Таблица 3

Распределение оценок россиянами социально-психологического самочувствия, \%

\begin{tabular}{|c|c|c|c|}
\hline \multirow{2}{*}{$\begin{array}{l}\text { Альтернативы ответов на вопрос: «Как бы Вы } \\
\text { охарактеризовали свое обычное повседневное } \\
\text { эмоционально-психологическое состояние?» }\end{array}$} & \multirow{2}{*}{$\begin{array}{c}\text { Среди } \\
\text { всех } \\
\text { опрошенных }\end{array}$} & \multicolumn{2}{|c|}{ Возрастные группы, лет } \\
\hline & & $51-60$ & старше 60 \\
\hline Ощущаю эмоциональный подъем & 4 & 4 & 1 \\
\hline Чувствую себя спокойно, уравновешенно & 44 & 39 & 33 \\
\hline Нахожусь в состоянии безразличия, апатии & 11 & 11 & 11 \\
\hline Ощущаю тревогу & 29 & 31 & 41 \\
\hline Чувствую раздражение & 9 & 12 & 13 \\
\hline Ощущаю чувство озлобленности & 2 & 3 & 3 \\
\hline Ощущаю чувство агрессии & 1 & 1 & 1 \\
\hline
\end{tabular}

Эти две возрастные группы схожи как по своим социально-психологическим, так и социально-экономическим характеристикам.

Из таблицы 3 видно, что социально-психологическое самочувствие респондентов возрастной группы 51-60 лет ненамного отличается от показателей всего массива. Вместе с тем, как было отмечено выше, с возрастом у человека растет чувство тревоги. Увеличивается и раздражение.

Предпенсионный период и сам уход на пенсию сопряжен для многих людей с переживаниями. Так, у работающего человека сложился определенный образ жизни, который в случае ухода на пенсию придется ломать. На службе он занимает какую-то позицию, постоянно общается с коллегами, имеет определенный социальный статус. С уходом на пенсию все это человек теряет, не говоря уже о потере зарплаты. Конечно, есть ряд людей, с удовольствием уходящих на пенсию. Скажем, человек не любит свою работу, плохо себя чувствует и пр. Но для большинства людей уход на пенсию - это испытание, снижение самооценки, которая тесно связана с уровнем самореализации человека 1 . Чтобы этого не произошло, люди и в пожилом возрасте продолжают работать. Не всегда это происходит из-за недостатка материальных средств. Некоторые пенсионеры не хотят покидать свою работу, даже если им материально помогают дети. По данным Росстата, в экономике работают 22,1\% чел. в возрасте 50-59 лет 2 . Если рассматривать численность работающих пенсионеров этой возрастной группы по видам занятости, то оказывается, то наиболее востребованы люди с образованием. Они дольше сохраняют свою трудовую активность. Так, с высшим образованием продолжают работать $33,5 \%$, со средним $-45,1 \%{ }^{3}$.

Выше мы писали, что люди уже в полувековой юбилей задумываются о том, удалась ли у них жизнь или нет. Чем старше становится человек, тем этот вопрос о результатах прошлой жизни становится для него более актуальным. Мы провели исследование самореализации среди людей пенсионного возраста. Респондентам был задан вопрос: «Удалась ли ваша жизнь?» Наше исследование самореализации людей старших возрастов показало, что более чем у $70 \%$ россиян жизнь, как правило, удается, ранее намеченные планы реализуются.

\footnotetext{
1 Козлова Т.З. Самореализация личности. - Социологическая энциклопедия. В 2 т. М.: Мысль. 2003. T. $2.862 \mathrm{c}$.

2 Россия в цифрах. 2017: краткий статистический сборник. М.: Росстат. 2017. С. 97.

3 Там же.
} 
Существует тесная связь между самооценкой человека и его самореализацией [Козлова 2003: 122-124].

В возрастную группу старше 60 лет входят люди разных старших возрастов (от 60 до 100 лет и, возможно, старше). Из табл. 3 видно, что в самой старшей возрастной группе социально-психологическое самочувствие гораздо ниже (33\%), чем по всему массиву. Растет чувство тревоги (41\%). Такие показатели самочувствия у самой старшей группы людей понятны и объяснимы. В старом возрасте слабеет здоровье, изменяют силы, подтачивают болезни, человек больше всего озабочен тем, чтобы не было хуже, лишь бы не стать бедным, немощным, одиноким. Одной из значимых проблем для этой возрастной группы становится забота о своем здоровье.

Выйдя на пенсию, люди стараются, пока позволяет здоровье, вести активный образ жизни. Так, в возрасте 60-72 лет продолжают работать 5,3\% пенсионеров$^{1}$. Ранее проведенное Росстатом исследование по проблемам занятости показало, что среди работников в возрасте 60 лет и старше требуются квалифицированные рабочие в таких отраслях, как сельское, лесное, охотничье хозяйства, рыбоводство и рыболовство ${ }^{2}$. Надо заметить, что в других возрастных группах численность занятых в этих отраслях меньше. Можно предположить, что молодежь не очень охотно идет работать в эти отрасли, т.к., во-первых, там не очень престижный вид труда, во-вторых, здесь требуются именно квалифицированные рабочие. Как известно, в ряде отраслей экономики в 1990-е гг. в связи с реорганизациями были растеряны квалифицированные кадры.

Если пенсионер не работает на государственной службе, то воспитывает внуков, помогает ухаживать за нездоровыми родственниками. Некоторые пенсионеры занимаются патриотическим воспитанием молодежи, входя в советы ветеранов.

Анализ социально-психологического самочувствия россиян по возрастным группам дает возможность дифференцированно представить состояние общества, его социально-психологическое самочувствие.

\section{Список литературы}

Ананьев Б.Г. 1997. О проблемах современного человекознания. М.: Наука. 379 с.

Зобов Р.А., Келасьев В.Н. 2008. Человекознание; самореализация человека: учебник (под общ. ред. В.Н. Келасьева). СПб: Изд-во СПбГУ. 436 с.

Козлова Т.3. 2003. Социальное время пенсионеров: этапы самореализации личности. М.: Институт социологии РАН. 228 с.

Латова Н.В. 2016. Влияние кризиса на удовлетворенность россиян своей жизнью и их социально-психологическое самочувствие. - Российское общество и вызовы времени. Книга третья (под ред. М.К. Горшкова, Н.Е. Тихоновой). М.: Весь Мир. С. 41-64.

Clemens W., Backes G.M. 1998. Altern und Gesellschaft, Gesellschaftliche Modernisierung durch Alterns Strukturwandel. Opladen: Leske+Budrich. 380 s.

Botwinick J. 1967. Cognitive Processes in Maturity and Old Age. N.Y.: Springer. 130 p.

Kuhlen R.G. 1968. Developmental Changes in Motivation during the Adult Years. - Middle Age and Aging (ed. by B.L. Neugarten). Chicago; London: University of Chicago Press. P. 115-136.

\footnotetext{
${ }^{1}$ Там же.

2 Обследование населения по проблемам занятости. М.: Росстат. 2005. 224 с.
} 
KOZLOVA Tatyana Zakharovna, Dr.Sci (Soc.), Leading Researcher of Sociological Institute - branch of the Federal Center of Theoretical and Applied Sociology, Russian Academy of Sciences (bld. 5, 24/35 Krzhizhanovskogo St, Moscow, Russia,117218; tatiana_kozlova@mail.ru)

\title{
SOCIAL AND PSYCHOLOGICAL WELL-BEING OF RUSSIANS BY AGE GROUPS
}

Abstract. The article examines the socio-psychological well-being of Russians by age groups: 19-30 years; 31-40 years; 41-50 years; 51-60 years; older than 60 years. The article is based on the materials of the sociological study conducted by the Institute of Sociology of the Russian Academy of Sciences in the end of 2016. The results of the research showed how the daily emotional and psychological state of a person changed with age. Younger and middle age groups are dominated by the calm state of mind. After 50 (closer to retirement) the share of worry and fear components in their socio-psychological state increases.

Keywords: Russians, age, socio-psychological state, optimism, worry

МУХАНОВА Мария Николаевна - кандидат социологических наук, старший научный сотрудник Института социологии ФНИСЦ РАН (117218, Россия, г. Москва, ул. Кржижановского, 24/35, кopn.5; mukhanova_m@rambler.ru)

\section{СЕЛЬСКОЕ НАСЕЛЕНИЕ В СТРУКТУРАХ НЕФОРМАЛЬНОГО СЕКТОРА НА РЫНКЕ ТРУДА АПК}

\begin{abstract}
Аннотация. Исследование неформального сектора и занятости в нем сельского населения опирается на базу данных Росстата, полученную в 2011-2016 гг. в результате обследования домохозяйств и индивидов по заказу правительства РФ. Методом интервью было опрошено сельское население в возрасте от 16 лет в 9 федеральных округах, в т.ч. Крымском ФО, в результате которого было выявлено, что снижение уровня занятости сельского населения в сельском хозяйстве и рост в других отраслях АПК обусловили отраслевую мобильность, трансформацию социальной структуры села и образование неформального сектора, где треть занятых - селяне.
\end{abstract}

Ключевые слова: структура занятости сельского населения, рынок труда, неформальный и формальный секторы, домохозяйства, доходы

$\mathrm{P}$ оссия в 2010-2013 гг. находилась в восходящем тренде, доходы и уровень жизни населения росли после кризиса 2008-2009 гг. Социальноэкономические изменения, происшедшие в стране во второй половине 2014 г, а также кризис 2015-2016 гг. актуализировали проблемы российского села и, в частности, занятости его населения. Контрсанкции, направленные на ограничение импорта продовольствия, а также беспрецедентные субсидии сделали сельское хозяйство в России выгодным бизнесом, несмотря на то что в результате инфляции цены на продовольствие выросли вдвое и продолжают расти. Образование сектора неформальной занятости сельского населения является частью процесса институционализации рыночной экономики в аграрном секторе, начавшегося в 1990-х гг. Занятость в неформальном секторе - распространенное явление в странах с переходной экономикой, где доминирует бедность и высокий уровень безработицы. Ее характерные особенности - нацеленность 